\title{
Synthesis of polyhedral oligomeric silsesquioxane-n-acetylcysteine conjugate with click chemistry and its antioxidant response and biocompatibility
}

\author{
İdil KARACA AÇARI ${ }^{1 *}$ (D), Sevgi BALCIOĞLU ${ }^{2}$ (D), Burhan ATEŞ ${ }^{3}$ (D), Süleyman KÖYTEPE ${ }^{3}$ (D), İsmet \\ YILMAZ $^{3}$ (D) Turgay SEÇKIN ${ }^{3}$ iD
}

${ }^{1}$ Vahap Kucuk Vocational School, Malatya Turgut Ozal University, 44210, Malatya, TURKEY

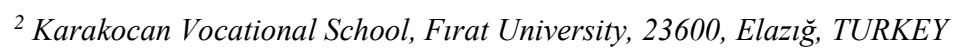

${ }^{3}$ Department of Chemistry, Faculty of Science, Inonu University, 44280, Malatya, TURKEY

\begin{abstract}
In this study, polyhedral oligomeric silsesquioxane- $N$-acetylcysteine (POSS-NAC) conjugate as a potential antioxidant molecule was synthesized from $N$-acetylcysteine (NAC) and aminofunctional POSS structure by click chemistry. The chemical structures and thermal properties of the synthesised POSS-NAC conjugate was characterized by spectroscopic and thermal analysis techniques. The antioxidant capacity of the POSS-NAC conjugate was also determined by the 2,2'-azinobis-(3-ethylbenzothiazoline-6-sulfonic acid) (ABTS) radical scavenging activity and reducing power methods. According to the reducing power method, POSS-NAC structure has lower reducing activity than standard ascorbic acid and trolox $(\mathrm{p}<0.001)$. It was found from the ABTS radical scavenging activity results that the synthesized POSS-NAC conjugate had a significantly higher radical scavenging effect than the standards ( $\mathrm{p}<0.001)$. Biocompatibility properties of the POSS-NAC structure were detected in vitro cell culture system with 3-(4,5-dimethylthiazol-2-yl)-2,5-diphenyltetrazolium bromide (MTT) test on L-929 mouse fibroblast cells. The synthesized POSS-NAC conjugate exhibits high antioxidant activity and good biocompatibility.
\end{abstract}

\section{Introduction}

Polyhedral oligomeric silsesquioxanes (POSS) carrying eight functional $\mathrm{R}$ groups such as alkyl, aryl or epoxide unit are essential structures for modern material design and synthesis studies [1-4]. The $R$ groups connected to the $\mathrm{Si}$ atoms in the POSS lattice structure, with the empirical formula $\mathrm{RSiO}_{1.5}$, are suitable for different modifications in advance technological applications [7-19]. It is suitable for use in many fields such as POSS, low dielectric materials, drug delivery system, biosensors, dental composites, tissue engineering, biomedical materials due to its smooth and controllable morphology, functionality with different groups, biocompatible structure, chemical and thermal stability [15-19]. Many POSS compounds have been synthesized in recent years due to these advantageous properties. In particular, the development of molecules with increased activity by binding catalysts, drugs or enzymes on eight functional groups of the POSS structure is of great importance [20].

$\mathrm{N}$-acetyl-L-cysteine ( $N$-acetylcysteine or NAC) as a natural important amino acid is the $N$-acetylated derivative of L-cysteine [21]. NAC is an antioxidant containing thiol and has been used for a long time in clinical treatments [22-24]. In addition, NAC is a powerful free radical scavenger thanks to its nucleophilic reactions with ROS [25]. Therefore, the development of new antioxidant structures connected to the NAC unit is of great importance in clinical and biomedical fields.

In this study, NAC containing POSS-NAC conjugate was synthesized by click chemistry. Click chemistry is particularly important in preparative methods. There is great interest in click chemistry in terms of high yields, short reaction times, selectivities and many functional group tolerances [26-28]. Chemical structure, thermal behaviors and surface morphology of the POSS-NAC conjugate were characterized with nuclear magnetic 
resonance spectroscopy (NMR), fourier transform infrared spectroscopy (FTIR), thermal analysis, scanning electron microscopy (SEM) and energydispersive X-ray spectroscopy (EDX) techniques. In addition the radical scavenging activity of synthesised conjugate structure was determined by ABTS and reducing power methods. The antioxidan activity results were compared with ascorbic acid and trolox standard substances. Biocompatibility of the POSSNAC structure was investigated on L-929 mouse fibroblast cells with in vitro cell culture system by MTT test.

\section{Materials and Methods}

\subsection{Materials}

Chemicals used in the synthesis of POSS-NAC structure and dimethyl sulfoxide (DMSO) suitable for cell culture study were obtained from the SigmaAldrich Chemical Company. Disodium hydrogen phosphate $\left(\mathrm{Na}_{2} \mathrm{HPO}_{4}\right)$, sodium hydrogen phosphate dihydrate $\left(\mathrm{NaH}_{2} \mathrm{PO}_{4} .2 \mathrm{H}_{2} \mathrm{O}\right)$ and trichloroacetic acid (TCA) used for determination of antioxidant activity were purchased from Merck Chemicals. Fetal Bovine Serum (FBS) was obtained from Biowest. 3-(4,5dimethylthiazol-2-yl)-2,5-diphenyltetrazolium

bromide (MTT) was purchased from AppliChem. Penicillin-Streptomycin was supplied from PAN Biotech. Dulbecco's Modified Eagle Medium (DMEM) was purchased from Capricorn Scientific. Mouse fibroblast cell line (L-929) Mus musculus mouse fibroblast cell line were sub cultured from a stock culture obtained from the Hacettepe University Faculty of Science. Other chemicals used in cell culture and antioxidan activity studies were obtained from Sigma-Aldrich Chemical Company.

\subsection{Instrumentation}

Infrared spectrum of the POSS, NAC and POSS-NAC conjugate were recorded in the range $4000-650 \mathrm{~cm}^{-1}$ with ATR accessory on Perkin Elmer 283 model Fourier transform-infrared spectrometer (FTIR). Verification of the POSS-NAC chemical structure was performed by NMR spectroscopy technique. ${ }^{1} \mathrm{H}-\mathrm{NMR}$ spectrum POSS, NAC and POSS-NAC structures were recorded on Bruker $300 \mathrm{MHz}$ NMR spectrometer and scanned from -0.5 to $13 \mathrm{ppm}$. DMSO- $\mathrm{d}_{6}$ was used as a solvent in ${ }^{1} \mathrm{H}-\mathrm{NMR}$ measurements. Surface structure and elemental mapping of obtained amino-functional POSS, POSS-NAC conjugate and NAC molecule were performed via a LEO-EVO 40 model scanning electron microscope and energy dispersive X-ray spectroscopy
(Bruker-125 eV). EDX spectrum measurements were performed in the range of $0.313 \mathrm{keV}$ and ZAF correction was used in these analyzes. In the study, the thermal properties and thermal stability of the obtained POSS-NAC conjugate were determined by thermal analysis methods and compared with the pure NAC and amino-functional POSS structure. As thermal analysis, differential scanning calorimetry (DSC), differential thermal analysis (DTA), and thermogravimetry analysis (TGA) were performed. DTA thermograms were recorded with Shimadzu DTA-50 device at an heating rate of $10^{\circ} \mathrm{C} / \mathrm{min}$ in air atmosphere. All DTA measurements were performed with $10 \mathrm{mg}$ sample and $\mathrm{Al}_{2} \mathrm{O}_{3}$ reference at $20-800^{\circ} \mathrm{C}$ temperature range. In the thermogravimetric analyses, Shimadzu TGA-50 model thermal analyser was used. The TGA studies were performed at a heating rate of $10{ }^{\circ} \mathrm{C} / \mathrm{min}$ at temperature range from 20 to $800{ }^{\circ} \mathrm{C}$ using $10 \mathrm{mg}$ sample in air atmosphere. DSC analysis of amino-functional POSS, NAC and POSS-NAC structure was performed at $5{ }^{\circ} \mathrm{C} / \mathrm{min}$ heating rate and under $25 \mathrm{~mL} / \mathrm{min}$ dynamic nitrogen atmosphere. DSC analyses were carried with $5 \mathrm{mg}$ sample from room temperature to $300{ }^{\circ} \mathrm{C}$. For the determination of antioxidant activity of synthesised POSS-NAC conjugates, BioScan Eon brand 96-well plate microplate reader was used. The inverted microscope systems (Olympus) are used for observing living cells. IKA brand rotary evaporator was used to remove the solvents used in the syntheses.

\subsection{Synthesis of the octa(3- aminopropyl)octasilsesquioxane (POSS- $\mathrm{NH}_{2}$ )}

For amino-functional POSS (POSS-NH ${ }_{2}$ ) synthesis, 3aminopropyltriethoxysilane (APS) was used. Firstly, $20 \mathrm{~mL}$ of APS was dissolved in $150 \mathrm{~mL}$ of methanol. To this solution was added $28 \mathrm{~mL}$ of concentrated $\mathrm{HCl}$. The reaction mixture was maintained at $50{ }^{\circ} \mathrm{C}$ for 8 hours. $\mathrm{PtCl}_{4}(0.5 \%$ by weight $)$ as catalyst was added in this solution an argon atmosphere. Reaction took place in the thermostat at $50{ }^{\circ} \mathrm{C}$ and a crystalline precipitate formed after one day. The product was filtered and washed with cold methanol. Then obtained POSS- $\mathrm{NH}_{2}$ precipitate was dried in a vacuum oven at $30^{\circ} \mathrm{C}$. The white product was neutralized by successively washing with $1 \mathrm{M} \mathrm{NaOH}$ solution $(3 \times 200 \mathrm{~mL})$, water $(6 \times 200$ $\mathrm{mL})$ and methanol $(6 \times 200 \mathrm{~mL})[29]$.

\subsection{Synthesis of POSS-NAC conjugate}

In this study, 1,3-dipolar cycloaddition click reaction between an alkyne and an azide groups, was used. POSS-NAC conjugate was synthesed from azide- 
functional POSS structure and alkyne group containing NAC molecules by azide-alkyne Huisgen cycloaddition reaction. These type reactions are of great interest in terms of high yields, short reaction times, selectivities and tolerance of many functional groups [27-28]. These reactions widely used in the synthesis of polymers with many compositions and topologies, from linear to non-linear macromolecular structures $[27-28,30]$. POSS-NAC conjugate synthesis was shown in Figure 1 and was carried out in three steps.

Step 1. The azide functional POSS (POSS-N $\left.{ }_{3}\right)$ structure was prepared from sodium azide $\left(\mathrm{NaN}_{3}\right)$ and octa(3-aminopropyl)octasilsesquioxane with the $1 / 8$ (POSS/ $\mathrm{NaN}_{3}$ ) molar ratio. $1 \mathrm{mmol}$ of aminofunctional POSS was dissolved in $10 \mathrm{~mL}$ of DMSO. 8 mmol $\mathrm{NaN}_{3}$ was added this solution. After obtaining the appropriate solubility, $0.01 \mathrm{~g} \mathrm{NH}_{4} \mathrm{Cl}$ was added. The reaction mixture was refluxed for 2 hours at $60^{\circ} \mathrm{C}$. The reaction was continued for 18 hours at room temperature. The active product was obtained by precipitation from the obtained yellow-orange liquid. The product was characterized by FTIR and ${ }^{1} \mathrm{H}-\mathrm{NMR}$ spectroscopic techniques after being washed and removed from its impurities. Thus, the azidefunctional POSS structure given in Figure 1 has been obtained.

Step 2. In order to connect NAC groups with the azidefunctional POSS structure, the NAC molecule was activated with propargyl bromide. For this reaction, 8 mmol NAC and $8 \mathrm{mmol}$ propargyl bromide were refluxed in $20 \mathrm{~mL} \mathrm{DMF}$ for $1 \mathrm{~h}$ at $100{ }^{\circ} \mathrm{C}$. The reaction was then continued at room temperature for 15 hours. Then, the solvent in reaction mixture was removed from product by rotary evaporator. The product was structurally characterized after being removed from its impurities by washing.

Step 3. In the third step; the products obtained in the first and second steps were allowed to react with each other at room temperature for 24 hours. The POSSNAC conjugate was obtained as a product according to synthesis scheme in Figure 1. The product was washed to remove impurities and then characterized by different instrümentation techniques.

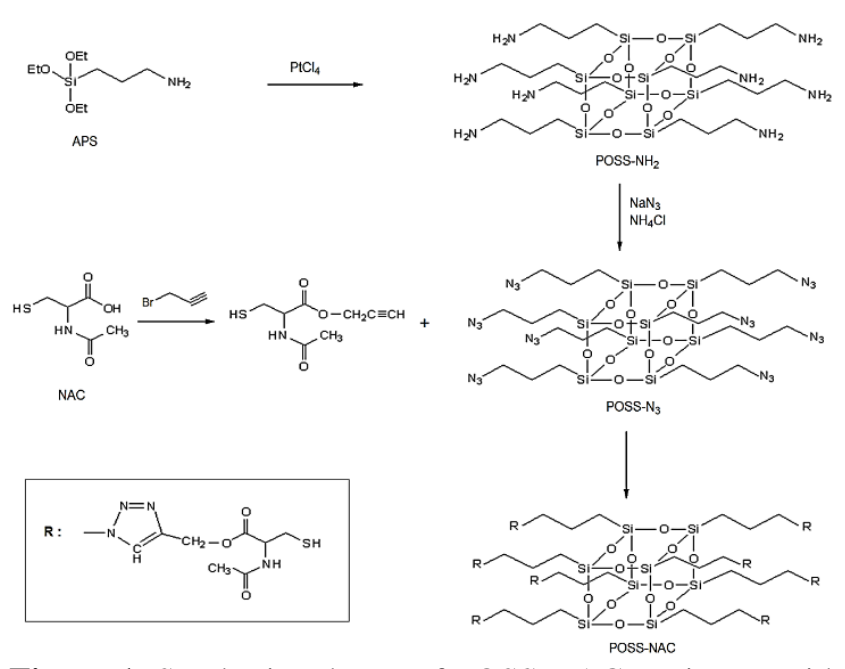

Figure 1. Synthesis scheme of POSS-NAC conjugate with click reaction.

\subsection{Antioxidant activity of POSS-NAC conjugate}

Radical scavenging activities of antioxidant structures were determined by the widely used ABTS and reduction power methods. The results were compared with ascorbic acid and trolox standard substances. Determination of antioxidant activity by ABTS method and reduction power method was determined respectively in accordance with the methods of Re et al. and Hwang [31-32].

\section{ABTS Method}

ABTS was produced by reacting $7.4 \mathrm{mM}$ ABTS with $2.6 \mathrm{mM}$ potassium persulfate in phosphate buffered saline (pH 7.4) and stored at dark for $18 \mathrm{~h}$, and then ABTS was diluted with distilled water to an absorbance of 0.700 at $734 \mathrm{~nm}$. For the experiment, 50 $\mu \mathrm{L}$ of standart and sample solutions were added to the ABTS and incubated for $30 \mathrm{~min}$ at dark. Then, absorbance were measured at $734 \mathrm{~nm}$. Finally, ABTS activity was calculated using the equation below. As a standard ascorbic acid and trolox solutions were used $(25,50,100,200,400,800$ and $1000 \mu \mathrm{M})$. Polymer samples were adjusted the optimum concentration for linear absorbance graphic and compared with the standarts as the same concentrations.

$\%$ free radical scavencing activity $=\left[\left(\mathrm{A}_{\text {control- }}\right.\right.$ $\left.\left.\mathrm{A}_{\text {sample }}\right) / \mathrm{A}_{\text {control }}\right]$ x 100

\section{Reducing Power}

In order to determine the ferric-reducing power of polymer samples, first, $0.2 \mathrm{M}$ and $2.5 \mathrm{ml}$ of phosphate buffer and $2.5 \mathrm{~mL}$ and $1 \%$ potassium ferricyanide were added to $1 \mathrm{~mL}$ of standard and sample solutions. Then, they were incubated in a water bath at $50^{\circ} \mathrm{C}$ for $20 \mathrm{~min}$ followed by adding $2.5 \mathrm{ml} 10 \%$ of TCA for stopping the reaction. The mixtures were centrifuged at 10000 rpm for $10 \mathrm{~min}$ and $2.5 \mathrm{ml}$ of supernatant were taken 
and mixed with $3 \mathrm{ml}$ of $\% 0.017$ ferric chloride $\left(\mathrm{FeCl}_{3} \cdot 6 \mathrm{H}_{2} \mathrm{O}\right)$. Tubes were mixed for $5 \mathrm{~min}$ and the absorbance was measured at $700 \mathrm{~nm}$.

\subsection{In vitro evaluation of cell viability of POSS- NAC conjugate}

In this study, the cytotoxicity values of the synthesized POSS-NAC conjugate, amino-functional POSS structure and pure NAC molecule were determined spectrophotometrically by MTT (thiazole blue tetrazolium bromide) test [33-34]. Mus musculus type mouse fibroblast cells (L-929) were used in the cell viability study. Firstly, the samples were sterilized under UV light for 1 hour by washing with sterile PBS (pH 7.4). Different concentrations of the sample (200, $100,50,25,10 \mu \mathrm{M})$ were prepared diluted with DMEM medium and prepared samples were incubated with DMEM medium in an oven containing 5\% CO2 at $37^{\circ} \mathrm{C}$ for 72 hours. The L-929 cell line was proliferated in the DMEM medium for the experiment until it became $80 \%$ confluent under the same conditions, then the cells were removed from flasks with a $0.25 \%$ trypsin-EDTA solution. Cells taken by centrifugation at $2000 \mathrm{rpm}$ for 5 minutes were then added to 96-well plates as $10^{4}$ cells / well and incubated for 24 hours in an oven containing $5 \% \mathrm{CO}_{2}$ at $37^{\circ} \mathrm{C}$. At the end of the incubation, the samples were exposed to the samples and the medium was incubated for an additional 24 hours under the same conditions. Then, $90 \mu \mathrm{L}$ of fresh medium was added to the plates by removing the medium from the cells. $10 \mu \mathrm{L}$ of $5 \mathrm{mg} /$ $\mathrm{mL}$ MTT solution prepared in PBS was added and incubated for 4 hours in the same conditions in the dark. Absorbances were measured in the Elisa microplate reader at $540 \mathrm{~nm}$ of purple color. The wells that were left in the incubator for 72 hours were added to the control wells and these wells were considered as $100 \%$ alive. \% Cell viability of the samples compared to the control on L-929 cells was calculated and cell morphologies were determined by JuliFL cell analyzer and\% confluent ratios were given. Living cell percentages were obtained based on the absorbance results.

\subsection{Statistical analysis}

Statistical analyses in antioxidant activity tests of POSS-NH $\mathrm{N}_{2}, \mathrm{NAC}$ and POSS-NAC conjugate were carried out using Graphpad Prism 5 software. Antioxidant activity test results were presented as mean values \pm standart deviation.

\section{Results and Discussion}

\subsection{Structural characterization of NAC, POSS- $\mathrm{NH}_{2}$ and POSS-NAC conjugate}

Synthesised amino-functional POSS, POSS-NAC conjugate and pure NAC structure were characterized by FTIR and ${ }^{1}$ H-NMR spectroscopy techniques. In addition, the thermal, structural and surface properties of these molecules were examined with TGA, DTA, DSC, SEM and EDX techniques. Figure 2 shows FTIR spectra of pure NAC, amino-functional POSS and POSS-NAC conjugate.

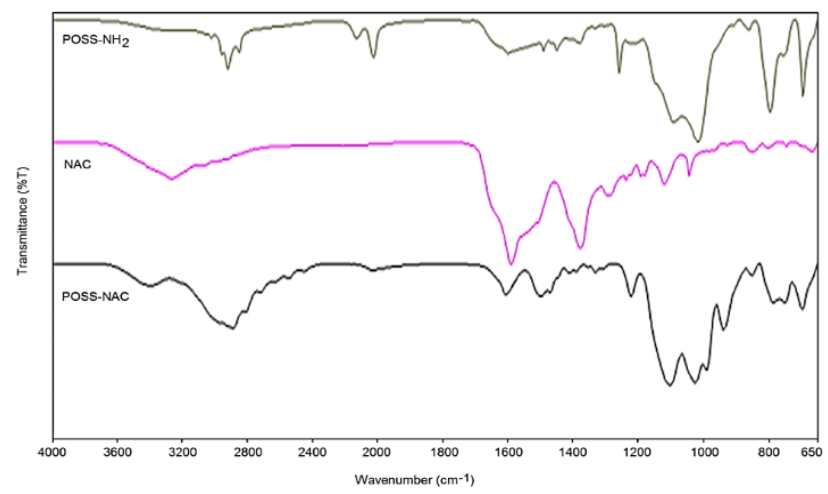

Figure 2. FTIR spectra of POSS-NH$H_{2}, \mathrm{NAC}$ and POSSNAC.

POSS-NAC conjugate as a potential antioxidant molecule was synthesized using amino-functional POSS and NAC structure as antioxidant. The synthesized POSS-NAC molecule structure was interpreted by comparing the FTIR spectra of pure $\mathrm{NAC}$ and POSS- $\mathrm{NH}_{2}$ structures. In Figure 2; In the FTIR spectrum of pure NAC structure, there are symmetrical and asymmetric tensile vibrations of amide, carboxylic acid and thio alcohol groups. - $\mathrm{SH}$ group was seen as a wide band between 3100- 3600 $\mathrm{cm}^{-1}$. In addition, amide I peaks at $1560 \mathrm{~cm}^{-1}$ and amide II peaks at $1460 \mathrm{~cm}^{-1}$ were detected. The carbonyl stress vibration of these amide groups and the carbonyl stress vibration in the carboxylic acid structure coincided to give a wide band at $1600 \mathrm{~cm}^{-1}$. In the NAC structure, aliphatic $\mathrm{C}-\mathrm{H}$ tensile vibrations were also observed in symmetrical C-H $2800 \mathrm{~cm}^{-1}$ and asymmetric C-H $926 \mathrm{~cm}^{-1}$. Three fundamental stress oscillations were observed in FTIR spectra of POSS structure. These are the $\mathrm{NH}_{2}$ group $\mathrm{CH}_{2}$ groups and Si$\mathrm{O}$ bonds. These are $3300 \mathrm{~cm}^{-1}$ moderate $\mathrm{N}-\mathrm{H}, 2850-$ $2960 \mathrm{~cm}^{-1}$ aliphatic C-H tensile vibrations and 1000$1100 \mathrm{~cm}^{-1}$ respectively. Stress vibrations of both NAC groups and POSS groups were seen in the FTIR spectrum of the POSS-NAC structure. In particular, the broad band of Si-O-Si groups was seen due to the 
POSS group in the structure. Amide I peak in NAC structure was seen in $1560 \mathrm{~cm}^{-1}$ and amide II peak in $1425 \mathrm{~cm}^{-1}$, while carbonyl groups were found in 1604 $\mathrm{cm}^{-1}$. In this structure, $\mathrm{Si}-\mathrm{O}-\mathrm{Si}$ and $\mathrm{Si}-\mathrm{O}$ peaks originating from POSS structure were found at 1056 $\mathrm{cm}^{-1}$ and $976 \mathrm{~cm}^{-1}$. As a result, it was proved with FTIR spectra that the desired POSS-NAC structure was obtained. Structural characterization of POSS- $\mathrm{NH}_{2}$, NAC, POSS-NAC conjugate was also made by ${ }^{1} \mathrm{H}-$ NMR (Figure 3, 4, 5). NAC, an important antioxidant, was bound to the POSS structure via amino groups. The product structure after this coupling was confirmed by NMR spectra. In ${ }^{1} \mathrm{H}-\mathrm{NMR}$ spectrum, the POSS structure yielded four basic peaks, including $\mathrm{NH}_{2}$ groups (Figure 3). There are singlet at $8.10 \mathrm{ppm}$, multiplet at $2.80 \mathrm{ppm}$, multiplet at $1.72 \mathrm{ppm}$ and multiplet at $0.70 \mathrm{ppm}$ peaks are attributed to $-\mathrm{NH}_{2}$, $\mathrm{CH}_{2}-\mathrm{N}, \quad-\mathrm{CH}_{2}-\mathrm{CH}_{2}-\mathrm{CH}_{2-}$ and $\mathrm{CH}_{2}-\mathrm{Si}$ protons, respectively [35]. Sharp peaks seen at 2.51 and 3.50 $\mathrm{ppm}$ are stem from the solvent [35]. In ${ }^{1} \mathrm{H}-\mathrm{NMR}$ spectrum of pure NAC structure, -SH peak at 2.44 ppm, $H$-C-N proton signal at $4.41 \mathrm{ppm}$, methyl group $\mathrm{C}-H$ peak at $1.98 \mathrm{ppm}$ and $\mathrm{CH}_{2}$ group $\mathrm{C}-\mathrm{H}$ multiplet proton peaks at $2.82 \mathrm{ppm}$ are seen (Figure 4 ). In the NMR spectrum of the POSS-NAC structure, proton peaks arising from the $-\mathrm{CH}_{2}-\mathrm{CH}_{2}-\mathrm{CH}_{2}$, $\mathrm{NAC}$ structure and 1,2,3-triazole ring groups are seen. First of all, it is understood from the $\mathrm{C}-\mathrm{H}$ proton in the ring structure of 1,2,3-triazole at 7,68 $\mathrm{ppm}$ that the POSS and NAC groups are connected [36]. POSS peaks in the structure of POSS-NAC obtained by a click reaction were observed in 2.51, 1.84 and 0.90. $0.90 \mathrm{ppm}\left(\mathrm{Si}-\mathrm{CH}_{2}\right)$, $1.84 \mathrm{ppm}\left(\mathrm{CH}_{2}-\mathrm{CH}_{2}-\mathrm{CH}_{2}\right)$ and $2.51 \mathrm{ppm}\left(\mathrm{CH}_{2}-\mathrm{N}\right)$ peaks in the NMR spectrum of the POSS-NAC structure are seen due to POSS functional groups [35]. The NMR spectrum of POSS-NAC in Figure 5 shows $4.20 \mathrm{ppm}(\mathrm{H}-\mathrm{C}-\mathrm{N}), 1.26 \mathrm{ppm}\left(\mathrm{CH}_{2}-\mathrm{S}\right), 2.15 \mathrm{ppm}(-$ $\left.\mathrm{CH}_{2}-\right)$ and $1.85 \mathrm{ppm}\left(-\mathrm{CH}_{3}\right)$ peaks due to the NAC structure. Besides these peaks, SH peak at $1.15 \mathrm{ppm}$ proves that NAC group is added to the structure [37]. As a result, acetyl group of NAC at about $1.85 \mathrm{ppm}$ was observed in POSS-NAC, which indicates that NAC was successfully conjugated to the POSS structure [38].

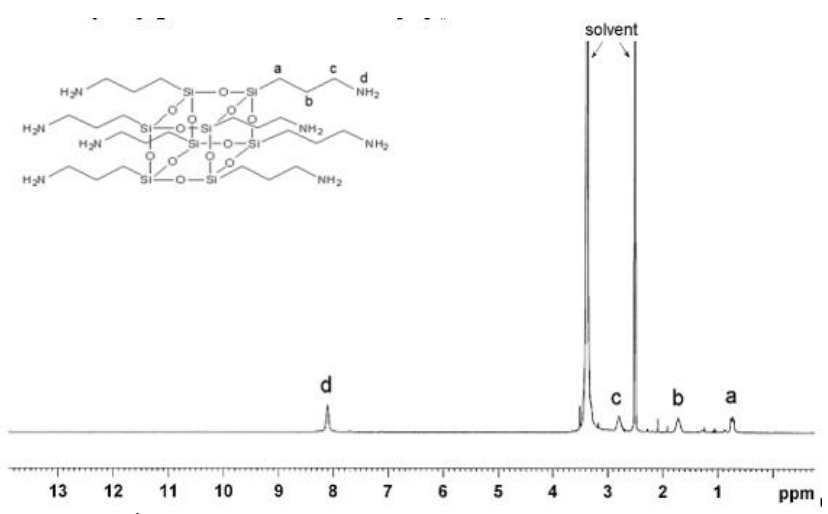

Figure 3. ${ }^{1} \mathrm{H}-\mathrm{NMR}$ spectrum of POSS-NH .
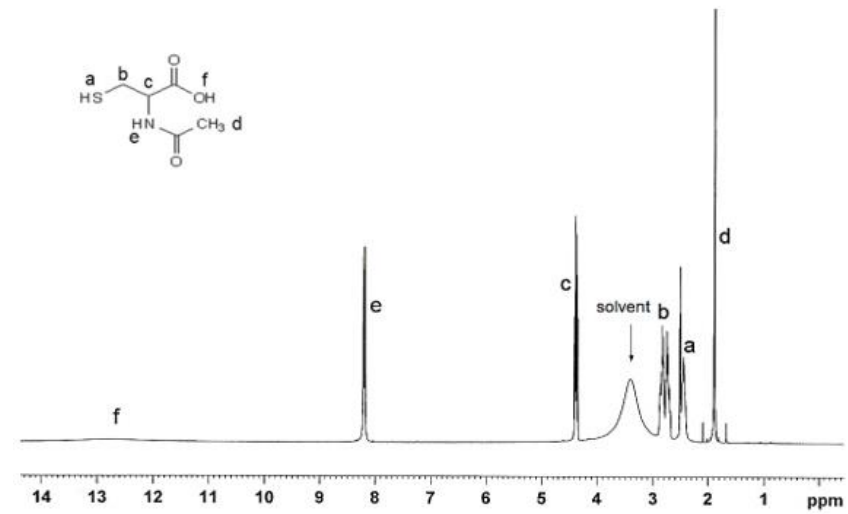

Figure 4. ${ }^{1} \mathrm{H}$-NMR spectrum of NAC.

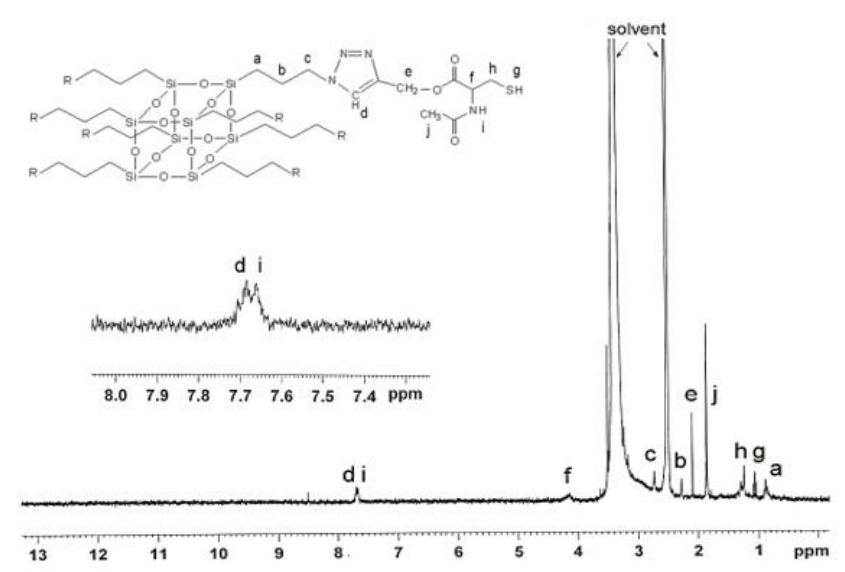

Figure 5. ${ }^{1} \mathrm{H}-\mathrm{NMR}$ spectrum of POSS-NAC conjugate.

\subsection{Thermal analysis of POSS- $\mathrm{NH}_{2}, \mathrm{NAC}$ and POSS-NAC conjugate}

TGA thermograms of amino-functional POSS, NAC and POSS-NAC are given in Figure 6. When these thermograms are examined, it is clearly seen in the thermogram of POSS- $\mathrm{NH}_{2}$ that the moisture in the structure is removed in the range of $30-100{ }^{\circ} \mathrm{C}$. Structurally, POSS- $\mathrm{NH}_{2}$ molecule has two basic organic groups as aliphatic $\mathrm{CH}_{2}$ groups and $\mathrm{NH}_{2}$ structure. In the thermogram structure, the 
decomposition intervals of these two groups are at 105$410{ }^{\circ} \mathrm{C}$ and $410-560{ }^{\circ} \mathrm{C}$. Since the NAC structure is a small aliphatic molecule, its thermal stability is low. Although the NAC structure decays to a great extent between $180-225^{\circ} \mathrm{C}$, it can be said that the structure is completely degraded after $225{ }^{\circ} \mathrm{C}$. POSS-NAC structure has gained much more thermal resistance than pure NAC structure. The structure begins to degrade at $285{ }^{\circ} \mathrm{C}$. After this temperature, it is decomposed in two steps by firstly the bound NAC and then aliphatic $\mathrm{CH}_{2}$ groups. The DTA thermograms of pure NAC, POSS- $\mathrm{NH}_{2}$ and POSS-NAC are shown in Figure 7.

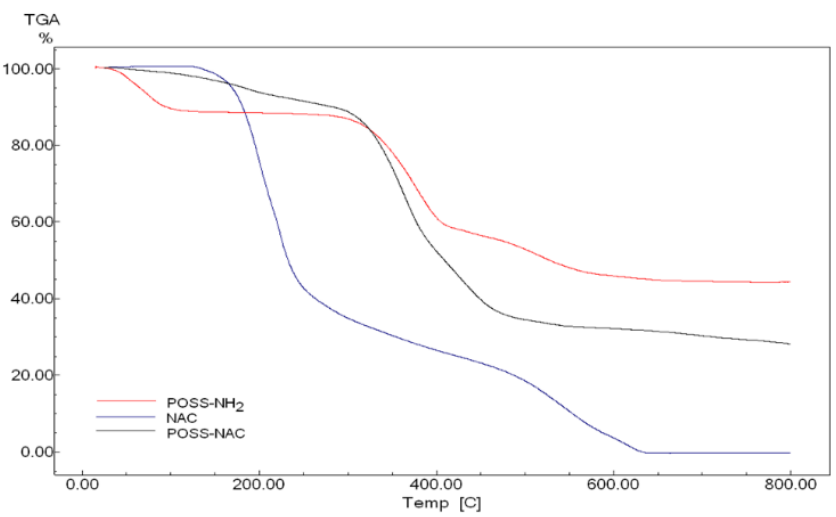

Figure 6. TGA thermograms of $\mathrm{POSS}-\mathrm{NH}_{2}, \mathrm{NAC}$ and POSS-NAC.

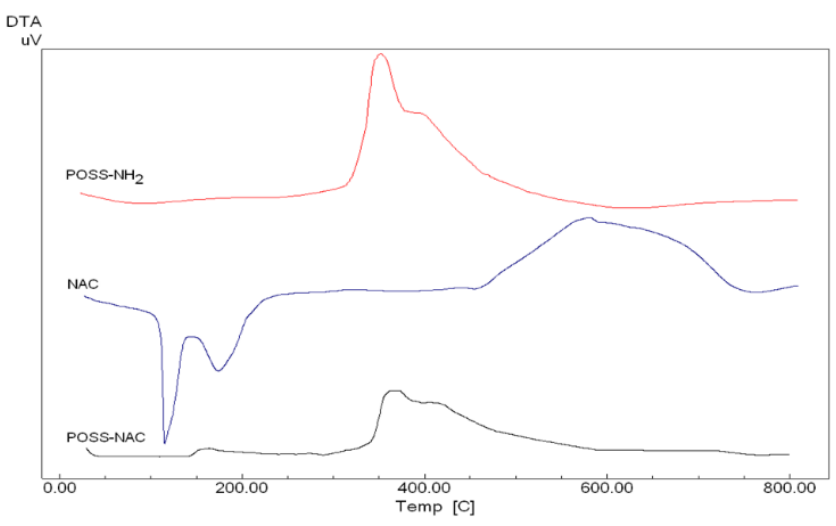

Figure 7. The DTA thermograms of POSS-NH POSS-NAC.

These thermograms appear to be consistent with TGA results. While POSS-NH $\mathrm{N}_{2}$ structure has a two-stage decomposition band, NAC structure has a melting peak and then thermal decomposition peak. In the POSSNAC structure, three basic degradation bands are observed. The first band is between $198-300{ }^{\circ} \mathrm{C}$ and is caused by a low thermal resistance triazole ring. The second band results from the degradation of NAC groups between $300-390{ }^{\circ} \mathrm{C}$. The final mass loss is the thermal degradation of organic groups due to POSS structure and was observed in the temperature range of $390-580{ }^{\circ} \mathrm{C}$. The DSC thermograms of pure NAC,
POSS- $\mathrm{NH}_{2}$ and POSS-NAC are shown in Figure 8. In these thermograms there is a band in POSS-NAC structure caused by the removal of moisture in the structure around $100{ }^{\circ} \mathrm{C}$ in the range of $30-400{ }^{\circ} \mathrm{C}$, while the degradation of organic side groups around $300{ }^{\circ} \mathrm{C}$ is observed. The thermogram of the NAC structure shows a sharp melting peak at $117^{\circ} \mathrm{C}$. In the POSS-NAC structure, the whole thermogram is different. There is no significant melting peak. In addition, the decomposition temperature of the molecule increased and went above $400{ }^{\circ} \mathrm{C}$. These results prove that the desired POSS-NAC structure is obtained thermally stable.

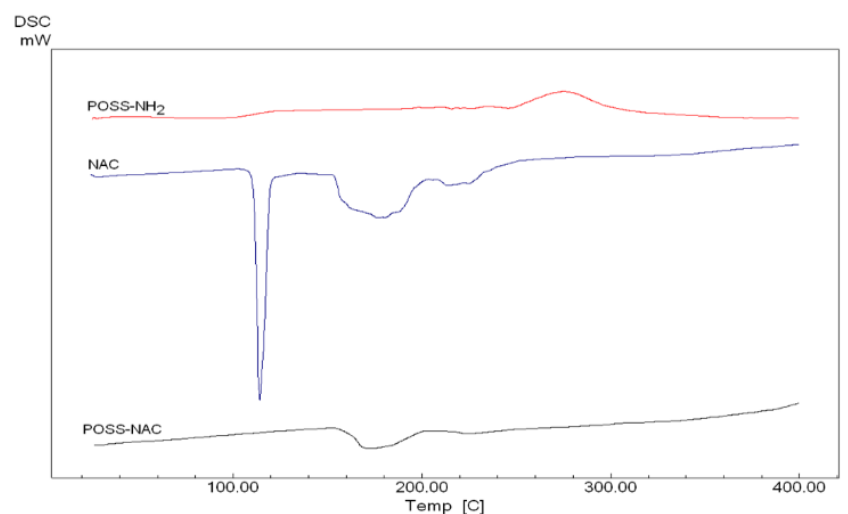

Figure 8. The DSC thermograms of POSS-NH $2, \mathrm{NAC}$ and POSS-NAC.

\subsection{Surface analysis of POSS-NH,$~ N A C$ and POSS-NAC conjugate}

The surface analysis results of the amino-functional POSS, NAC and POSS-NAC structure were given in Figure 9. Examining Figure 9, we can see that the SEM images of the synthesised POSS-NAC conjugate are different from the initial structures and are more crystalline and planar. POSS- $\mathrm{NH}_{2}$ structure has morphology in the form of small sharp pieces. The NAC structure shows particulate morphology. The resulting product is different and homogeneous from these structures. The differentiation in the structure proves the formation of a new structure, but homogeneous appearance shows the purity of the product. Figure 10 shows the elemental maps and EDX spectra of pure NAC, amino-functional POSS and POSS-NAC structure. In the POSS amino structure, C, $\mathrm{N}, \mathrm{O}$ and $\mathrm{Si}$ elements originate from the parent structure, while the peaks of the chlorine element are the opposite anions bound to the amines in the end group. In Figure 10(b), in the EDX spectrum of pure NAC structure, C peaks at $0,270 \mathrm{keV}, \mathrm{N}$ at $0,290 \mathrm{keV}$, $\mathrm{O}$ at $0,523 \mathrm{keV}$ and $\mathrm{S}$ at $0,149 \mathrm{keV}$ and $2,307 \mathrm{keV}$. These peaks are also evident in POSS-NAC structure. In the POSS-NAC structure, we see the peaks of $\mathrm{C}$ element at $0.271 \mathrm{keV}, \mathrm{N}$ at $0.290 \mathrm{keV}, \mathrm{O}$ at $0.124 \mathrm{keV}$, 
$\mathrm{S}$ at $0.130 \mathrm{keV}$ and $2.307 \mathrm{keV}$, and $\mathrm{Si}$ element at 0.090 $\mathrm{keV}$ and $1,741 \mathrm{keV}$ due to the POSS structure. This result proves the desired structure. In the EDX mapping images of the conjugate, a quite different surface image was obtained compared to the starting materials. This shows us the formation of a new molecule and the proof of the purity of the structure obtained by the homogeneous distribution of the elements.
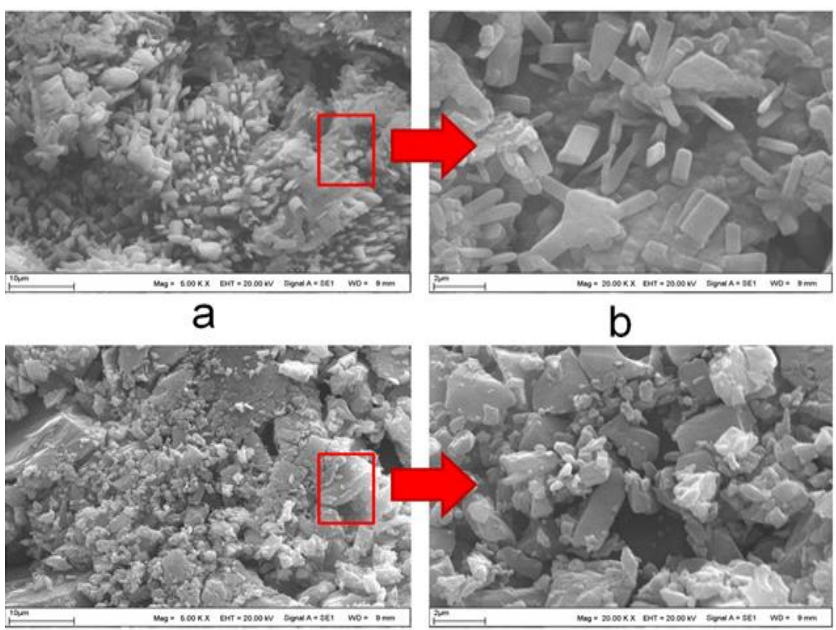

C

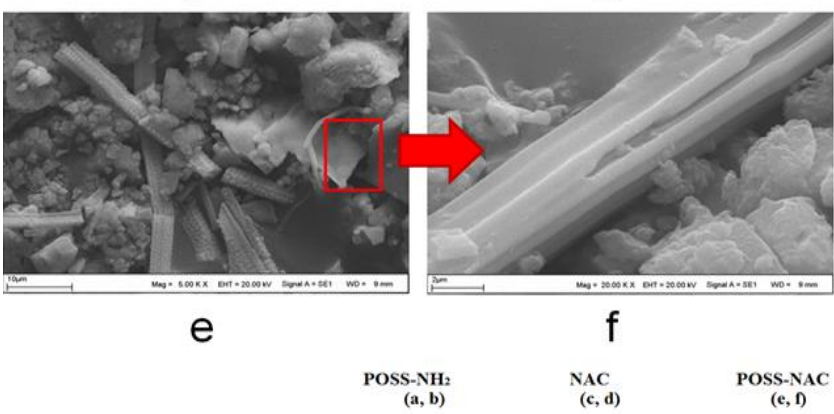

Figure 9. SEM images at different magnification rates for POSS-NH ${ }_{2}, \mathrm{NAC}$ and POSS-NAC.
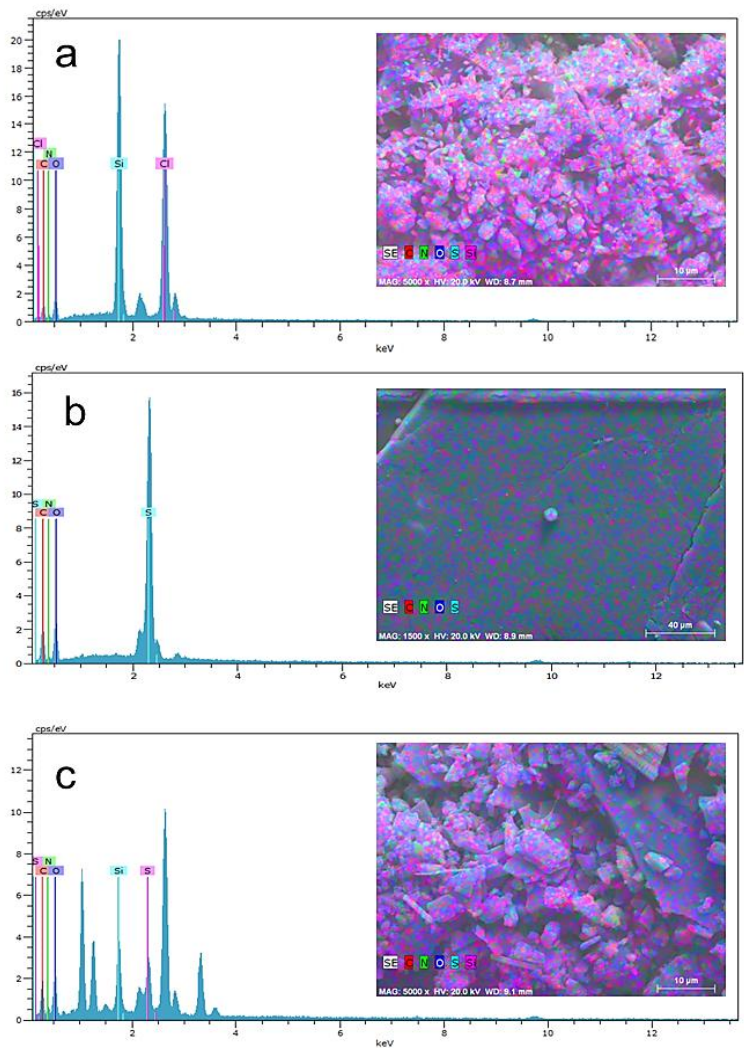

Figure 10. EDX-element mapping images for $\mathrm{POSS}-\mathrm{NH}_{2}$ (a), NAC (b) and POSS-NAC (c).

\subsection{Antioxidant activity properties of $\mathrm{POSS}-\mathrm{NH}_{2}$, NAC and POSS-NAC conjugate}

Antioxidant activity results were given in Table 1. In ABTS radical scavenging experiment, IC50 values of conjugate and NAC were calculated by using \% inhibition graphic and were compared with standart antioxidants such as ascorbic acid and trolox. NAC and POSS-NAC conjugate exhibited very similar IC50 values and these vaules were lower than standard antioxidants. According to the reducing power results, POSS-NAC structures showed more reducing power than amino functional POSS. Wherease, their activities were lower than standard actioxidants. As a result, NAC-functionalized POSS has high antioxidant properties in the compared with amino functional POSS due to conjugation of POSS with NAC.

\subsection{Cytotoxicity properties of POSS-NH $\mathrm{NH}_{2}, \mathrm{NAC}$ and POSS-NAC conjugate}

The $\%$ cell viability values and cell images of cytotoxicity test performed in L-929 fibroblast cells were shown in figures 11 and 12 respectively. We observed that the cell viability was $50 \%$ at the concentration of $200 \mu \mathrm{M}$ of the amino functional POSS structure, while the cell viability of POSS-NAC conjugates was approximately $100 \%$ in the whole 
working range. Therefore, the POSS-NAC structure exhibited biocompatible properties. In the POSS-NAC conjugate, cell viability was $100 \%$. Thus, the cell viability level of the amino functional POSS structure was parallel with POSS-NAC.

Table 1. ABTS radical scavenging activity and reducing power for POSS-NH, $\mathrm{NAC}$ and POSS-NAC.

\begin{tabular}{lcc}
\hline & ABTS & Reducing Power \\
& IC50 $(\mu \mathrm{M})$ & Abs/mM sample \\
\hline POSS-NH 2 & $>5000$ & $0.007 \pm 0.001$ \\
POSS-NAC & $295.46 \pm 3.00$ & $0.160 \pm 0.002$ \\
NAC & $306.20 \pm 9.06$ & $0.327 \pm 0.004$ \\
Ascorbic acid & $622.05 \pm 12.57$ & $0.474 \pm 0.002$ \\
Trolox & $1070.78 \pm 0.03$ & $0.610 \pm 0.014$ \\
\hline
\end{tabular}

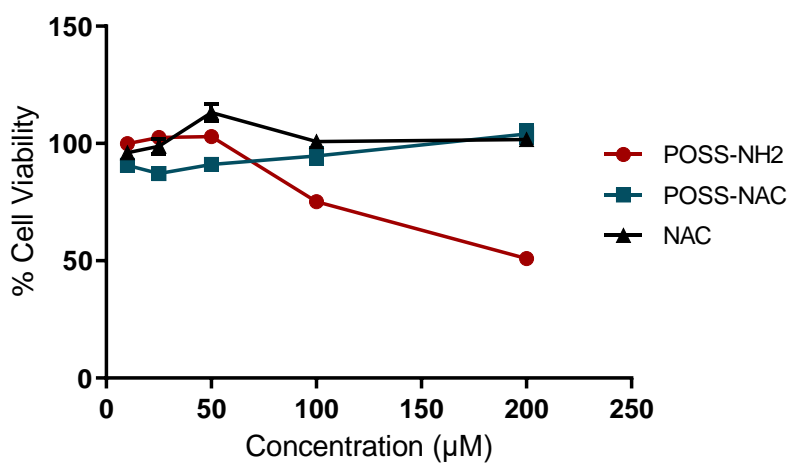

Figure 11. \% Cell viability values of POSS-NH 2, POSSNAC and NAC.

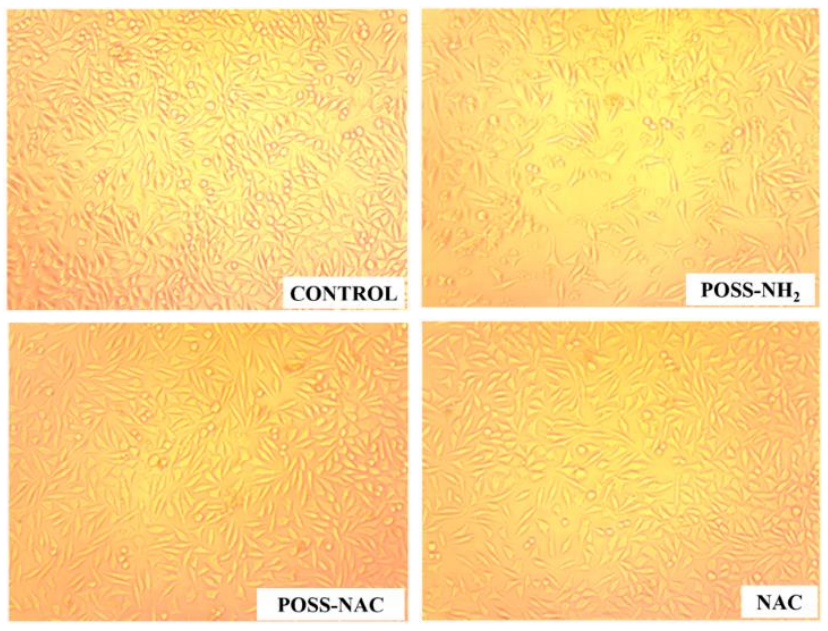

Figure 12. Microscope images of L-929 fibroblast cells incubated for $24 \mathrm{~h}$ with $200 \mu \mathrm{M}$ POSS- $\mathrm{NH}_{2}$, POSS-NAC and NAC.

\section{Conclusions}

In the study, POSS-NAC conjugate as a potential antioxidant molecule was synthesized using click chemistry from amino functional POSS and NAC. The accuracy of the synthesis was checked with FTIR, ${ }^{1} \mathrm{H}$ NMR, SEM / EDX and thermal analysis (DTA / TGA / DSC) techniques. Spectrum interpretations for amino functional POSS and NAC are consistent with the literature [39-41]. We understand that POSS-NAC conjugate has been successfully synthesized in the study from the suitable of the characterization results. No articles related to NAC binding to octa(3aminopropyl)octasilsesquioxane have been found. Navath et al; Dendrimer-NAC conjugates were synthesized using NAM with PAMAM dendrimer poly (amidoamine) dendrimer [42]. Desai et al. Supported chemoprevention in head and neck cancers by encapsulating NAC into poly (DL-lactic-co-glycolic acid) PLGA in their studies [43]. Cheng and colleagues have shown that NAC, an important antioxidant containing thiol, reduces poly (methylmethacrylate) PMMA toxicity [44]. Within the scope of the study, antioxidative activity was gained by NAC binding to amino functional POSS structure. Biocompatibility is very important in assessing the toxicity or irritation potential of the synthesized materials. Biocompatibility of the POSS structure is one of the factors that makes it widely used in various biomedical (drug delivery systems, dental composites, biosensors, biomedical device and tissue engineering) applications [45]. In vitro use of cells is common in assessing biocompatibility. For example; Kim and colleagues have demonstrated the biocompatibility of modified POSS constructs in mouse fibroblast cell (L-929) cells [46]. Punshona et al; mercaptopropyl isobutyl and octahydroxypropyl studied the biocompatibility of POSS constructs in human lens epithelial cells [47]. Skaria et al. performed cell toxicology studies of octaanhydried functional POSS molecule in myoblast (C2CI2) and human osteoblast cells (MG63) cells and showed no toxicity [48]. In our study, we observed the high biocompatibility of the POSS-NAC conjugate in vitro in L-929 mouse fibroblast cells. As a result, it is 
thought that the synthesized POSS-NAC conjugate with biocompatibility and antioxidative properties has a very high potential for use in many areas (biomaterials, drug delivery systems, biosensors, etc.).

\section{Acknowledgment}

The study was financially supported by Inonu University's scientific research projects unit (BAP) with code 2013/157.

\section{Conflicts of interest}

The authors state that did not have conflict of interests

\section{References}

[1] Kuo S.W. and Chang F.C. POSS related polymer nanocomposites. Prog. Polym. Sci., 36(12) (2011) 1649-1696.

[2] Cordes D.B., Lickiss P.D. and Rataboul F. Recent developments in the chemistry of cubic polyhedral oligosilsesquioxanes. Chem. Rev., 110(4) (2010) 2081-2173.

[3] Shea K.J. and Loy D.A. Bridged polysilsesquioxanes. Molecular-engineered hybrid organic-inorganic materials. Chem. Mater., 13(10) ( 2001) 3306-3319.

[4] Ebunoluwa A., Biswajit S. and Paschalis A. Polyhedral Oligomeric Silsesquioxane (POSS)Containing Polymer Nanocomposites. Nanomaterials, 2(4) (2012) 445-475.

[5] Shockey E.G., Bolf A.G., Jones P.F., Schurab, J.J., Chaffee K.P., Haddad T.S. and Lichtenhan J.D. Functionalized polyhedral oligomeric silsesquioxanes: New graftable POSS hydride, POSS alfa-olefin, POSS epoxy, and POSS chlorosilane macromers and POSS-siloxane triblocks. Appl. Organomet. Chem., 13(34) (1999) 311-327.

[6] Linchtenhan J.D., Otonari Y.A. and Carr M.J. Linear hybrid polymer building blocks: Methacrylate-functionalized polyhedral oligomeric silsesquioxane monomers and polymers. Macromolecules., 28(24) (1995) 8435-8437.

[7] Wu J. and Mather P.T. POSS polymers: Physical properties and biomaterials applications. Polym. Rev., 49(1) (2009) 25-63.

[8] Kanamori K. and Nakanishi K. Controlled pore formation in organotrialkoxy-silane-derived hybrids: from aerogels to hierarchically porous monoliths. Chem. Soc. Rev., 40(2) (2011) 754770 .
[9] Mantz R.A., Johns P.F., Chaffee K.P., Lichtenhan J.D., Gilman J.W., Ismail I.M.K. and Burmeister M.J. Thermolysis of polyhedral oligomeric silsesquioxane (POSS) macromers and POSS-siloxane copolymers. Chem. Mater., 8(6) (1996) 1250-1259.

[10] Leu C.M., Reddy G.M., Wei K.H. and Shu C.F. Synthesis and dielectric properties of polyimidechain-end ethered polyhedral oligomeric silsesquioxane nanocomposites. Chem. Mater., 15(11) (2003) 2261-2265.

[11] Köytepe S., Demirel M.H., Gültek A., Seçkin T. Metallo-supramolecular materials based on terpyridine functionalized polyhedral silsesquioxane. Polym Int., 63(4) (2014) 778787.

[12] Li G.Z., Wang H.N. and Pittman C.U. Polyhedral oligomeric silsesquioxane (POSS) polymers and copolymers. J. Inorg. Organomet. Polym., 11 (3) (2001) 123-154.

[13] Li G.Z., Yamamato T., Nozaki K. and Hikosaka M. Crystallization of ladder like polyphenyl silsesquioxane (PPSQ)/isotactic polystyrene (iPS) blends. Polymer., 42(20) (2009) 8435-8441.

[14] Liang K., Toghian H., Li G. and Pittman C.U. Synthesis, morphology, and viscoelastic properties of cyanate ester/polyhedral oligomeric silsesquioxane nanocomposites. $J$. Polym. Sci., 43(17) (2005) 3887-3898.

[15] McCusker C., Carrol J.B. and Rotello V.M. Cationic polyhedral oligomeric silsesquioxane (POSS) units as carriers for drug delivery processes. Chem. Commun., 28(8) (2005) 996998.

[16] Fong H., Dickens S.H. and Flaim G.M. Evaluation of dental restorative composites containing polyhedral oligomeric silsesquioxane methacrylate. Dent. Mats., 21(6) (2005) 520-529.

[17] Zou Q.C., Yan Q.J., Song G.W., Zhang S.L. and Wu L.M. Detection of DNA using cationic polyhedral oligomeric silsesquioxane nanoparticles as the probe by resonance light scattering technique. Biosens. Bioelectron., 22(7) (2007) 1461-1465.

[18] Sarkar S., Buriesci G., Wojcik A., Aresti N., Hamilton G. and Seifalian A.M. Manufacture of small calibre quadruple lamina vascular bypass grafts using a novel automated extrusion-phaseinversion method and nanocomposite polymer. J. Biomech., 42(6) (2009) 722-730.

[19] Ghanbari H., Kidane A.G., Burriesci G., Ramesh B., Darbyshire A. and Seifalian A.M. The anti-calcification potential of a silsesquioxane nanocomposite polymer under in 
vitro conditions: Potential material for synthetic leaflet heart valve. Acta Biomater., 6(11) (2010) 4249-4260.

[20] Li G., Wang L., Ni H. and Pittman Jr C.U. Polyhedral oligomeric silsesquioxane (POSS) polymers and copolymers: A review. J. Inorg. Organomet. Polym., 11(3) (2002) 123-154.

[21] Kerksick C. and Willoughby D. The antioxidant role of glutathione and $\mathrm{N}$-acetyl-cysteine supplements and exercise induced oxidative stress. J. Int. Soc. Sports Nutr., 2(2) (2005) 3844.

[22] Ater B., Abraham L. and Ercal N. Antioxidant and free radical scavenging properties of $\mathrm{N}$ acetylsysteine amide (NACA) and comparison with N-acetylcysteine (NAC). Free Rad. Res., 42(4) (2008) 372-377.

[23] Kelly G.S. Clinical applications of Nacetylcysteine. Altern. Med. Rev., 3(2) (1998) 114-127.

[24] Flanagan R.J. and Meredith T.J. Use of Nacetylcysteine in clinical toxicology. Am. $J$. Med., 91(3C) (1991) 131-139.

[25] Auroma O.I., Halliwell B., Hoey B.M. and Butler J. The antioxidant action of $\mathrm{N}$ acetylcysteine: its reaction with hydrogen peroxide, hydroxyl radical, superoxide and hypochlorous acid. Free Radic. Biol. Med., 6(6) (1989) 593-597.

[26] Kiskan B., Gacal B., Asan M., Gunaydin E.C., Yilmaz I. and Yagci Y. Synthesis and characterization of pyrrole and thiophene functional polystyrenes via "click chemistry". Polym. Bull., 67(4) (2011) 609-621.

[27] Hein C.D., Liu X-M. and Wang D. Click chemistry, a powerful tool for pharmaceutical sciences. Pharm. Res., 25(10) (2008) 22162230.

[28] Caselli E., Ramognoli C., Vahabi R., Taracila M.A., Bonomo R. and Prati, F. Click Chemistry in Lead Optimization of Boronic Acids as $\beta$ Lactamase Inhibitors. J. Med. Chem., 58(14) (2015) 5445-5458.

[29] Seçkin T., Gültek A. and Köytepe S. Synthesis and Characterization of Novel Hyperbranched Polyimides Based on Silsesquioxane Nanocomposite Networks. Turk. J. Chem., 29(1) (2005) 49-59.

[30] Zhang X. and Zhang Y. Applications of AzideBased Bioorthogonal Click Chemistry in Glycobiology. Molecules., 18 (6) (2010) 71457159.

[31] Re R., Pellegrini N., Proteggente A., Pannala A., Yang M. and Rice-Evans C. Antioxidant activity applying an improved ABTS radical cation decolorization assay. Free Radic. Biol. Med., 26(10) (1999) 1231-1237.

[32] Hwang J.Y. Antioxidative activity of roasted and defatted peanut kernels. Food Res. Int., 34(7) (2001) 639-647.

[33] Wataha JC., Craig RG. and Hanks CT. Precision of and new methods for testing in vitro alloy cytotoxicity. Dent. Mater., 8(1) (1992) 65-70.

[34] Juciute R., Bukelskiene V., Rutkunas V., Trumpaite-Vanagiene R. and Puriene A. In vitro evaluation of cytotoxicity of permanent prosthetic materials. Baltic Dent. Maxillofac. J., 13(3) (2011) 75-80.

[35] Hirohara T., Kai T., Ohshita J. and Kaneko Y. Preparation of protic ionic liquids containing cyclic oligosiloxane frameworks. RSC Adv., 7 (2017) 10575-10582.

[36] Oussadi K., Montembault V. and Fontaine L. Synthesis of poly(oxyethylene phosphate)-gpoly(ethylene oxide) via the "grafting onto" approach by "click" chemistry. J. Polym. Sci. A Polym. Chem., 49 (2011) 5124-5128.

[37] Mahou R. and Wandrey C. Versatile Route to Synthesize Heterobifunctional Poly(ethylene glycol) of Variable Functionality for Subsequent Pegylation. Polymers., 4 (2012) 561-589.

[38] Kunz S., Maturi M.M., Schrader I., Backenköhler J., Tschurl M. and Heiz U., Same ligand - Different binding: A way to control the binding of $\mathrm{N}$-acetyl-cysteine (NAC) to $\mathrm{Pt}$ clusters. J. Colloid Interface Sci., 426 (2014) 264-269.

[39] Gültek A., Seçkin T. and Adıgüzel H.İ. Design and characterization of amino and chloro functionalized rhombohedral silsesquioxanes. Turk. J. Chem., 29(4) (2005) 391- 399.

[40] Oehninger L., Stefanopoulou M., Alborzinia H., Schur J., Ledewing S., Naikawa K., MunozCastro A., Köster R.W., Baumann K., Wölfl S., Sheldrick W.S. and Ott I. Evaluation of arene ruthenium(II) N-heterocycliccarbene complexes as organometallics interacting with thiol and selenol containing biomolecules. Dalton Trans., 42(5) (2013) 1657-1666.

[41] Demirel M.H., Köytepe S., Gültek A. and Seçkin T. Synthesis and stimuli- responsive properties of the phenanthroline based metallosupra molecular polymers. J. Polym. Res., 21(2) (2014) 345-355.

[42] Navath R.S., Kurtoğlu Y.E., Wang B., Kannan S., Romero R. and Kannan R.M. Dendrimersdrug conjugates for tailored intracellular drug release based on glutathione levels. Bioconjugate Chem., 19(12) (2008) 2446-2455. 
[43] Desai K.G.H., Mallery S.R and Schwendeman S.P. Formulation and characterization of injectable poly(DL-Lactide-co-glycolide) 1mplants loaded with N-Acetylcysteine, a MMP inhibitor. Pharm. Res., 25(3) (2008) 586-597.

[44] Cheng Y., Yang H.C., Cho J.H., Lee S.H. and Lim B.S. The effect on N-Acetylcysteine addition on the polymerization behavior of PMMA bone cement. Macromol. Res., 20(9) (2012) 928-938.

[45] Ghanbari H., Cousins BG. and Seifalian AM. A nanocage for nanomedicine: polyhedral oligomeric silsesquioxane (POSS). Macromol. Rapid Commun., 32(14) (2011) 1032-1046.

[46] Kim SK., Heo SJ., Koak JY., Lee JH., Lee YM., Chung DJ., Lee JI. and Hong S.D. A biocompatibility study of a reinforced acrylicbased hybrid denture composite resin with polyhedraloligosilsesquioxane. J. Oral. Rehabil., 34(5) (2007) 389-395.

[47] Punshona G., Vara D.S. Sales K.M., Kidane A.G., Salacinski H.J. and Seifalian A.M. "Interactions between endothelial cells and a poly (carbonate-silsesquioxane-bridgeurea)urethane". Biomaterials., 26(32) (2005) 6271-6279.

[48] Skaria S. and Schricker S.R. Synthesis and characterization of 1norganic-organic hybrid materials derived from polysilsesquioxanes (POSS). J. Macromol. Sci. A: Pure Appl. Chem., 47(5) (2015) 381-391. 